\title{
Right time, right space? Developing an online transition course for new undergraduates
}

\author{
Kim Shahabudin \\ University of Reading, UK \\ Sonia Hood \\ University of Reading, UK \\ Michelle Reid \\ University of Reading, UK
}

\begin{abstract}
This case study describes the development of a pre-entry transition course for new undergraduate students and its delivery online using a commercial open online course platform. Use of this 'third space' platform, and the additional in-house support that accompanied it, were essential in creating a professional-looking course to maximise interest among an entire cohort of undergraduates at the start of their academic careers, while the pre-entry timing aimed to engage students before they became engrossed in subject learning. The course had dual aims: to support students in the development of new academic skills and to build a sense of community and identification with the University before arrival. Videos of current students and academic tutors provided a face-to-face introduction to the university while articles and activities on academic skills were informed by professional learning development experience and expertise. Non-compulsory enrolment attracted $64 \%$ of eligible students, $40.2 \%$ of which marked $90 \%$ or more of the course as completed. The course is now undergoing revision in response to student feedback for next year's iteration.
\end{abstract}

Keywords: Transition; first year experience; study skills; undergraduate; online teaching; MOOC; widening participation; diversity; inclusion; orientation; induction; community; online mentoring. 


\section{Introduction}

Concerns over the transition to university-level study are not new, particularly in reference to successful widening participation (Yorke and Longden, 2008; Thomas and May, 2010; Thomas, 2012). Recent studies have noted the extension of these concerns to the entire student demographic (HEPI and Unite Students, 2017). Issues include lack of academic confidence, failure to recognise the differences between school- and university-level academic practices and difficulties integrating into the university community (Quinn et al., 2005; Yorke and Longden, 2008; Thomas, 2012). These issues have the potential for negative impact not only on retention but also on the success levels of completers (Thomas et al., 2017).

One approach is to offer pre-entry guidance. However, practicalities dictate that pre-entry, on-campus initiatives cannot encompass the whole cohort so the tendency is to focus on a section of the cohort, for instance BTEC students, mature students or students from lowparticipation postcodes. While this strategy can enable targeted advice, it also runs the risk of damaging academic confidence further with its implications of expected failure and does nothing to encourage feelings of belonging with the wider university community, a noted source of student resilience (Thomas, 2012).

At our institution, we observed instances of excellent practice by individual academic teams in terms of skills training embedded in first year subject modules. However, to encourage a true level playing-field, we felt it was important to provide timely access to effective skills induction to all new undergraduates (Thomas and May, 2010). Study Smart is our response: a short online pre-entry course combining academic skills induction with community building activities and the chance to network with peers ahead of arrival on campus.

\section{Study Smart}

Study Smart was launched for the first time to new undergraduates in August 2017. It was delivered through the FutureLearn platform, more commonly used for Massive Open Online Courses (MOOCs). This course was neither massive nor open but limited to our 
own new undergraduates. All new Part 1 campus-based entrants were emailed a direct invitation to enrol $(n=4202)$. Invitees thus included students from a very wide range of disciplines from Politics to Pharmacy, Business Studies to Biomedical Sciences, Computer Science to Classics, Film, Theatre and Television to Food Sciences. Enrolment was not compulsory but students were strongly encouraged to join through a series of emails, beginning early in the summer with a teaser trailer. At the closure of enrolment, the course had 2694 participants (64\% of eligible students). Of these, $40.2 \%$ marked $90 \%$ or more of the course as completed, with $50.5 \%$ completing $50 \%$ or more.

The course was developed by members of the university's Study Advice team (the authors) in collaboration with the university's Open Online Courses (OOC) team. Course design and content was informed by small-scale research, drawing on focus groups and surveys with current undergraduates, and our extensive experience of working with new Part 1 students to support transitions to university study. We also commissioned current Typography students to produce some animations. Like a MOOC, the course was organised in 'weeks', though all three of these were released at the same time so that students could complete them at their own pace; we estimated that completion should take around nine hours in total (approximately three hours per week). Weeks were divided into 'steps' with around 20 short steps in each week. These used a variety of formats to engage participants and support inclusivity: videos featuring academic tutors and current students, quizzes, infographics, animated videos, click and listen activities and interactive discussions as well as more text-driven articles.

To engage students when they were keen to learn but before they started their subject courses, enrolment opened three weeks before the start of term. It remained open until the middle of autumn term to include any later enrolment. Comments and discussion activities were moderated and responded to by the Study Advice team with the help of a small team of six student mentors, recruited from the university's pool of Peer Assisted Learning mentors. Prior to the course launch, the mentors attended a half-day training session in which they were informed about the rationale of the course, given an outline of the content and shown some of the resources. It was important that they understood that their role was to be supportive as well as informative, so focus was placed on the tone of their 
communication, and the in-house OOC team offered examples of comments from other MOOCs to prepare them.

The course was designed to have a longer shelf-life than one-off induction sessions. Enrolled students retained access to the course for the whole of their first year, being able to return to guidance once they had assignments to help them put the information in context.

\section{Using the MOOC platform}

Delivering the course via the FutureLearn platform enabled us to offer students a polished and attractive, professionally-made, final product. As a small student-facing team offering a popular and well-used service, we have developed a range of innovative initiatives for delivering learning development teaching and support and for widening access to the service. However, these have all been produced using small funding awards which do not extend as far as employing external trainers or expert personnel. While we have had great success with this approach we were aware that, to engage such a broad group of participants, appearance and delivery would be as important as content. Using FutureLearn's platform gave us access to the invaluable experience and expertise of the university's in-house OOC team. Through them we worked with external filmmakers (who included previous students at the university) to turn our vague ideas into engaging videos. The university's Design and Print team produced professional graphics (Figure 1). Once the course content had been built, enrolment was managed by FutureLearn who also provided course management tools. 
Figure 1. Professionally designed graphics.

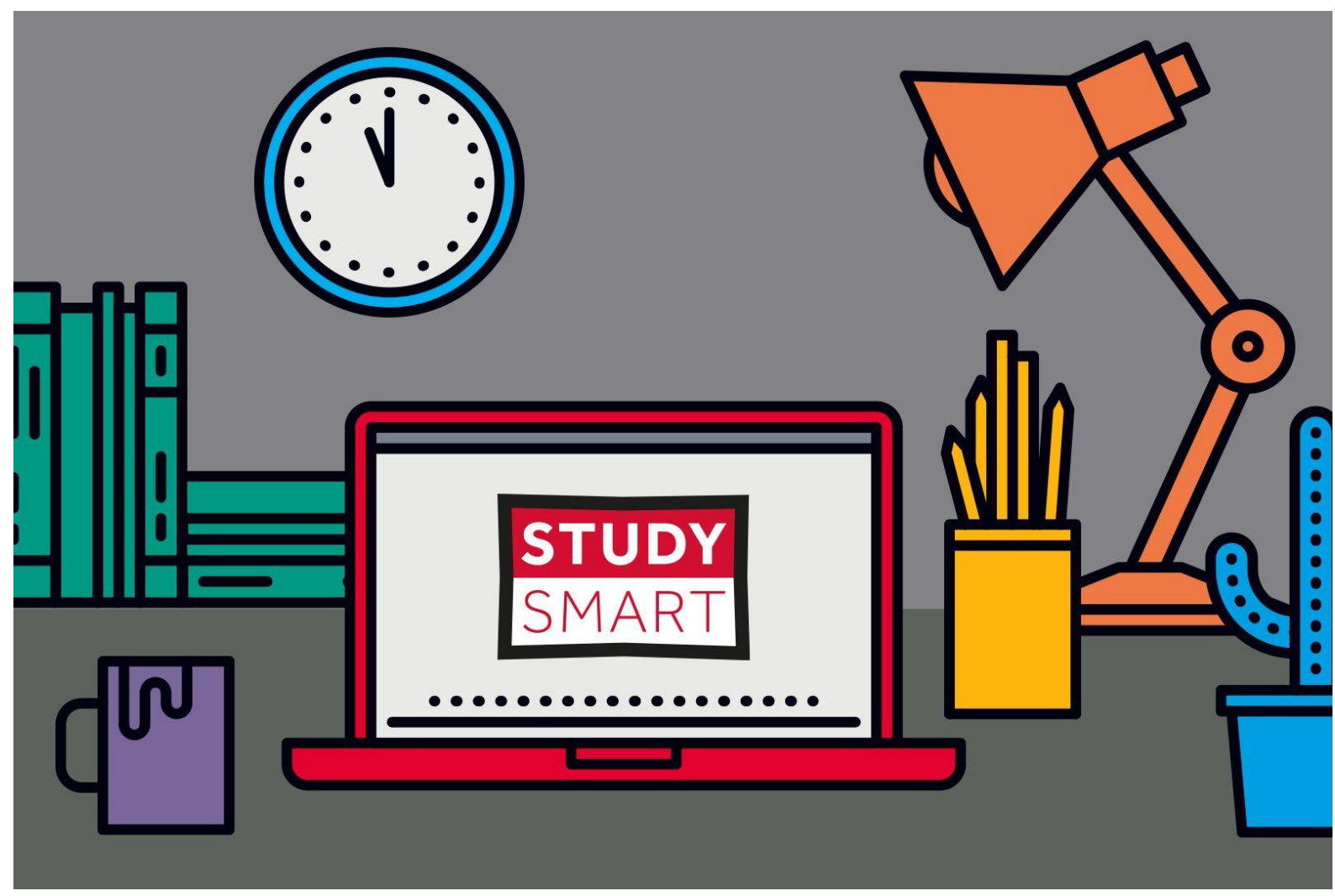

Unsurprisingly, this did not come for free: from FutureLearn there was a charge for hosting and an additional fee per student enrolled and there were further costs for the filmmakers and design. The project was funded by the university's 'Access Fund' as a potentially valuable strategy for addressing the BAME attainment gap in addition to its further benefits for inclusive learning (Berry and Loke, 2011; Stevenson, 2012). The Access Fund also supported the employment of a 0.5 FTE Study Adviser on a permanent post, to free up existing members of the team for resource development, and give us the capacity to meet increased demand on the service as a consequence of wider awareness of the support available.

For the Study Advice and $\mathrm{OOC}$ teams, collaborative working on the project was a valuable experience in itself. Through our collaboration, we were able to add our experience of working directly with new undergraduate students to their experience of producing engaging and effective online learning resources. The success of this approach was recognised in March 2018 when the two teams received a Collaborative Team Award for Teaching and Learning from the university. 


\section{Building a sense of community}

One of the key outcomes for Study Smart was to respond to potential difficulties in establishing a feeling of belonging and identification with the university community for students from diverse groups, a key factor in student retention (Yorke and Longden, 2008; Thomas, 2012). Three elements of the course played a role in achieving this aim. The first (discussed in more detail in the next section) aimed to unite students across disciplines with a common academic identity by surfacing the overarching principles behind all university-level study. The second aimed to personalise the abstract idea of the community with a series of videos showing current members of the university in campus settings. These included 'Vice-Chancellor Welcome' videos which book-ended the course; 'Walking Tours' which focused on a particular aspect of study (using the library, attending seminars, managing time), filming students and staff on campus; 'Tutor Tutorials' in which academic tutors from variety of disciplines spoke about the importance of particular academic practices; and 'Student Experience' videos with five students from various disciplines discussing their individual experiences of transition, providing peer-to-peer guidance comparable to an older sibling or school alumnae (Figure 2).

Figure 2. Screenshots from Student Experience videos.

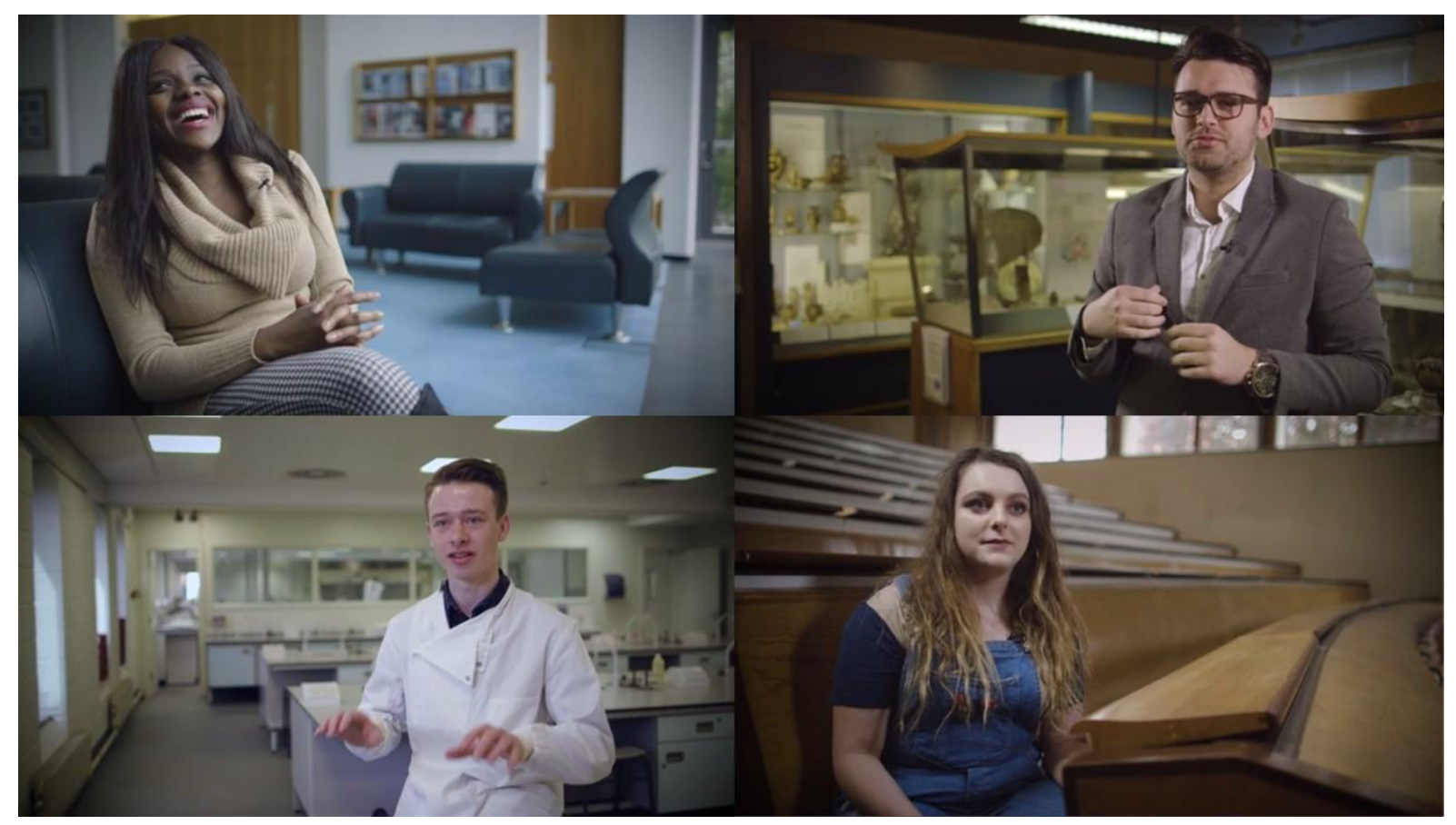


The third element aimed to promote interaction between students via the discussion boards and comments sections. Comments were enabled on every step, with some designated specifically as discussion activities: for instance, in one discussion, students identified an example of common knowledge in their discipline; in another they shared tips for avoiding procrastination. We were impressed by the level of engagement with this element: there were almost 4500 comments in total over the three 'weeks' of the course from just over 1000 individual authors: relatively low for a conventional MOOC but higher than we expected for this less confident participant group. Our six excellent student mentors were crucial in this, sharing their own experiences and encouraging interaction and continued discussion.

\section{Principles into practice}

To promote a sense of shared academic identity, we organised content around three underpinning principles for university-level study: academic integrity, communication for audience and purpose, and independent learning. Each section started with an explanation of the principle and its importance in university-level study, before contextualising with discussions and demonstrations to develop an understanding of how it might work in practice.

By introducing the concept of academic integrity at the very start of the course, we hoped to transform the old punishment-driven narratives about plagiarism into an aspirational trope about becoming academic. The section introduced the five values of academic integrity, showing their relation to more specific practices for research including evaluating sources, critical note-making, reasons for referencing, and the concept of disciplinespecific common knowledge (ICAI, 2012).

The second week took as its starting point the principle of appropriate communication for audience and purpose. From this starting point, we looked at communication in all areas, from speaking up in seminars to writing assignments (Figure 3). An area that emerged as a surprising source of anxiety in student focus groups was emailing tutors. Some students went so far as to say that they had been deterred from asking their tutors for help by being uncertain how to address them. As an issue that might affect students in all disciplines, 
deciding how to communicate with your tutor was a valuable vehicle for thinking about audience and purpose and how they might relate to style and tone.

\section{Figure 3. Screenshot from animation on communication at university.}

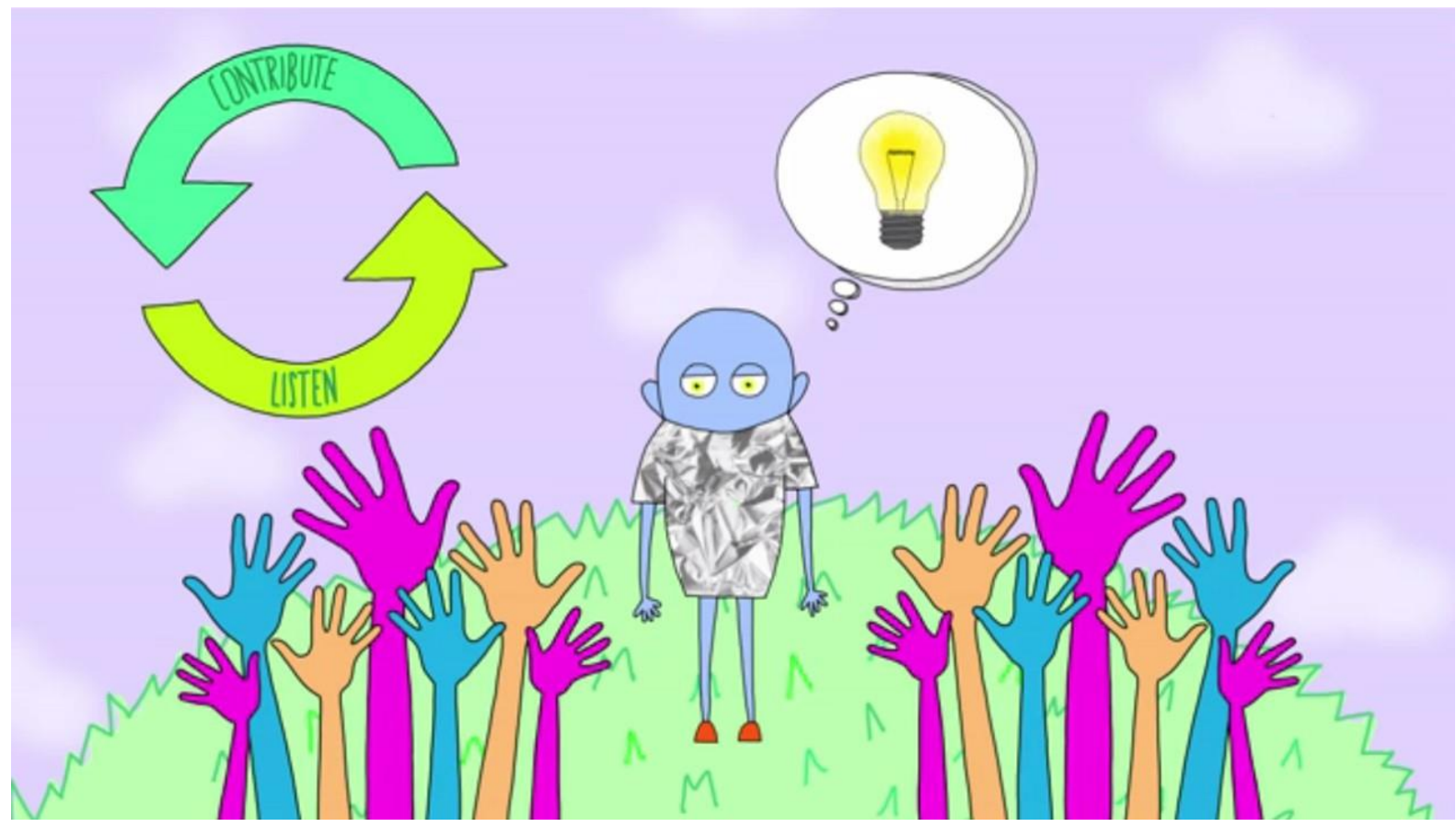

The final week looked at independent learning, the one thing all new undergraduates cite when asked how they think university will be different. We aimed to expand the narrow perception of independent learning as 'no-one will remind you about your deadlines' to show how independence is both a principle for academic study and a practical concern: applying to thinking, reading and writing as well as workload management. Articles, discussions and videos looked more closely at use of study time and critical thinking. The section also dealt with the tricky question of balancing independence with seeking available support when you need it.

\section{Challenges and successes}

Developing a centrally-funded major learning development resource in collaboration with others who had particular professional expertise seemed a dream opportunity. However, our original idea that we would be doing some research, developing some content and 
sitting back while others delivered it, proved distinctly utopian. Tasks we thought had been delegated to others turned out to require more of our involvement than anticipated.

Working with multiple collaborators meant we were not in control of timings. While we had a set of milestones to work towards, activities were often diverted by short-notice requests. In the final push, we were doing last-minute editing over the bank holiday weekend, a day or so before launch. This meant that our most pressured time for content development led straight into the greatest demand for responding to comments in the first weeks after the course opened, which then led into our busiest time for teaching at the start of Autumn term. By October we were grateful for the Freshers' Flu as a welcome opportunity for a rest.

Also time-consuming (but rewarding) was recruiting staff support for the project. Public backing from senior management was crucial in establishing Study Smart as a universitywide initiative, but entailed much report writing (Thomas et al., 2017). We took a different approach to persuading academics, giving a series of well-attended information and demonstration sessions with homemade cakes and biscuits provided. These interactions were time-consuming but also rewarding, raising both the profile and the reputation of the Study Advice service beyond the topic of Study Smart.

The discussion boards and the potential for offence (intentional or unintentional) were a source of concern pre-launch. While the OOC team drew confidence from their prior experience of participants self-policing boards, we were concerned that this younger and less socially-experienced cohort might find this difficult. In fact, participants treated the discussion boards as an extension of study and were polite and thoughtful of others. Disappointingly, we were not able to convert the majority of comments into conversations, despite the best efforts of our excellent student mentors who shared their own experiences and worked hard to encourage interaction with prompt questions. Participants were unexpectedly candid about their anxieties around the transition to university, with comments like: 'I'm feeling nervous, particularly about the social side and meeting new people, but I'm also really excited as I think it's going to be a bit of an adventure!' We decided to repay this candour by responding to every comment. Given a total of almost 4500 comments, this turned out to be quite a task, and we could not have done it without 
our brilliant mentors (Figure 4). However, our eagerness to respond to student comments quickly may have been a factor in inhibiting the development of peer discussion. This practice may need to be reconsidered for future iterations.

Figure 4. Typical student comment with reply from student mentor.

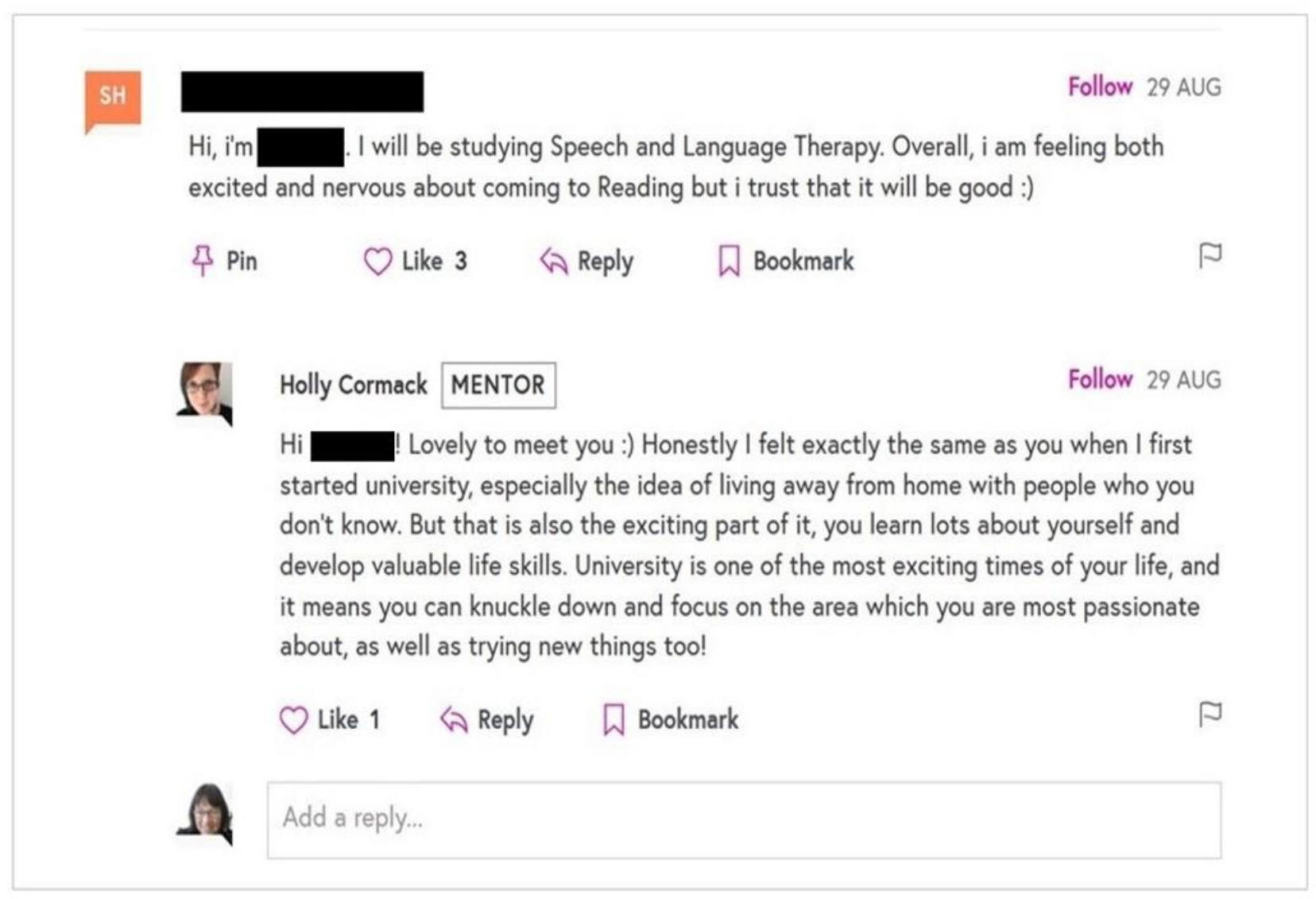

\section{Evaluation and future plans}

The first year of Study Smart was intended as a pilot to be reviewed and revised. We used a variety of methods to gain feedback to inform the next iteration, which revealed some expected and some surprising results. Two questionnaires (the first step in week 1 and the last step in week 3) framed the course, offering a self-audit of academic confidence. $94 \%$ of students who completed the later questionnaire indicated that their confidence had increased. However, the comparatively small number (16\% of $50 \%+$ completers but only $7 \%$ of total enrolled participants) means that this result can only treated as indicative. 
More comments came from a wider survey of the university's 'welcome week' activities. These suggested that we had more work to do in making the course appeal to all disciplines, with some students from science-based disciplines stating that they felt it did (or would, in the case of those who had not enrolled) not have relevant content for them. For the next iteration, we have revised content to add a wider range of examples and make the relevance of existing content for students in science-based disciplines more explicit. International students were also reluctant to enrol, feeling that the study skills component in pre-sessional English language courses they had undertaken should be sufficient. We have been working with colleagues providing pre-sessional English courses to promote the course to students about to enter undergraduate studies and show how it differs from previous teaching. These comments indicated that we have more work to do on framing the course to show its function as an induction to undergraduate study at our university, and to our academic community.

We had a substantial amount of data from the course itself on participant engagement. In common with most MOOCs, participation declined towards the end of the course and with all three 'weeks' released at once we did not have the natural weekly prompts to participants that conventional MOOCs use to retain engagement. We also found that certain formats were less popular. Surprisingly these included the quizzes, which we had expected to offer a more engaging interactive experience. As a consequence, we are reducing text and removing some steps in each section and seeking ways to crossreference later steps in earlier ones.

The course itself yielded a great deal of positive feedback via unsolicited comments (including many from BAME, international and mature students) (Figure 5). 


\section{Figure 5. Unsolicited testimonial from Study Smart participant.}

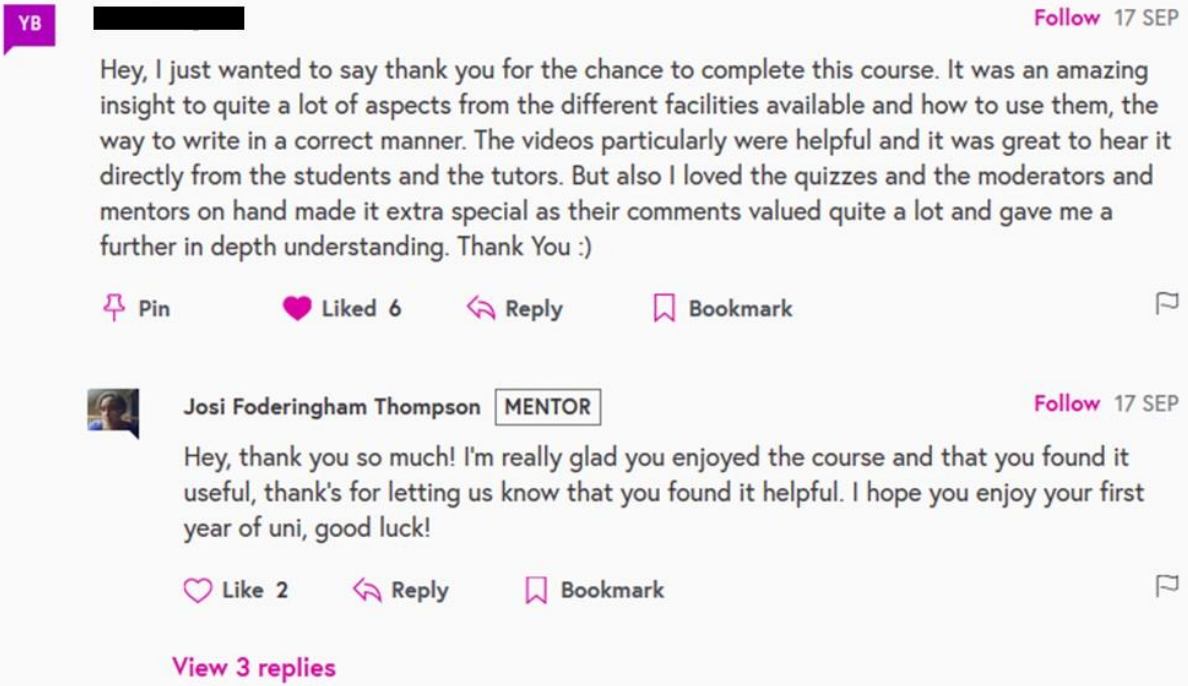

An important part of course evaluation was to assess its impact as a first year experience intervention, rather than just a transition resource. Figures showing the number of individual accesses made after enrolment closed (for the three sections of the course respectively: $538 ; 612 ; 573$ ) were greatly in excess of the number of additional completions (27 additional completions of $50 \%+, 28$ additional completions of $90 \%+$ ). This suggests that a significant number of students, who may have already completed much of the course, were using it as we had hoped and returning to it over the course of the year as they were able to relate the guidance to their actual studies.

Looking to the future, funding for the course has been confirmed for the next academic session and there is longitudinal research planned to track the progress of students who have undertaken the course through their undergraduate careers. It will take some time to discover whether Study Smart has had the positive impact on BAME attainment that originally motivated its funding. What we can state with certainty is that, through the course, we have, as a small learning development team of four (three of whom are parttime), reached a much greater number of students at the crucial point of transition than we could have done through our other teaching initiatives. For those students we are optimistic, both that raised awareness of learning development services will have a positive impact in the long term on undergraduate study success and that the course will 
have achieved its more immediate aims: reducing anxiety about the unknown, developing understanding of the differences between school and university and building identification with the university community.

\section{References}

Berry, J. and Loke, G. (2011) Improving the degree attainment of black and minority ethnic students. London/York: Equality Challenge Unit/Higher Education Academy. Available at: https://www.ecu.ac.uk/wp-content/uploads/external/improving-degreeattainment-bme.pdf (Accessed: 1 October 2018).

Higher Education Policy Institute (HEPI) and Unite Students (2017) Reality check: a report on university applicants' attitudes and perceptions. Oxford: HEPI. Available at: http://www.hepi.ac.uk/wp-content/uploads/2017/07/Reality-Check-ReportOnline1.pdf (Accessed: 1 October 2018).

International Center for Academic Integrity (ICAI) (2012) The fundamental values of academic integrity. Available at: https://academicintegrity.org/fundamental-values/ (Accessed: 20 October 2018).

Quinn, J., Thomas, L., Slack, K., Casey, L., Thexton, W. and Noble, J. (2005) From life crisis to lifelong learning: rethinking working-class 'drop out' from higher education. York: Joseph Rowntree Foundation. Available at: https://www.jrf.org.uk/report/rethinking-working-class-drop-out-university (Accessed: 1 October 2018).

Stevenson, J. (2012) Black and minority ethnic student degree retention and attainment. York, Higher Education Academy. Available at: https://www.heacademy.ac.uk/system/files/bme summit final report.pdf (Accessed: 1 October 2018).

Thomas, L. (2012) Building student engagement and belonging in higher education at a time of change. London: Paul Hamlyn Foundation. Available at: 
https://www.heacademy.ac.uk/system/files/what works final report.pdf (Accessed: 1 October 2018).

Thomas, L., Hill, M., O'Mahony, J. and Yorke, M. (2017) Supporting student success: strategies for institutional change. London: Paul Hamlyn Foundation. Available at: https://www.heacademy.ac.uk/system/files/hub/download/what works 2 full report.pdf (Accessed: 1 October 2018).

Thomas, L. and May, H. (2010) Inclusive learning and teaching in higher education. York: Higher Education Academy. Available at: https://www.heacademy.ac.uk/system/files/inclusivelearningandteaching finalreport. pdf (Accessed: 1 October 2018).

Yorke, M. and Longden, B. (2008) The first-year experience of higher education in the UK: final report. York: Higher Education Academy. Available at: https://www.heacademy.ac.uk/system/files/fyefinalreport 0.pdf (Accessed: 1 October 2018).

\section{Author details}

Kim Shahabudin has been working as a Study Adviser at the University of Reading since 2006, supporting students to develop effective and appropriate study practices for university. She has a special interest in transition issues for mature students returning to study. Kim is a University Teaching Fellow.

Sonia Hood has been a Study Adviser at the University of Reading for 7 years, having worked previously at the University of West London in a similar role. She is in the final stages of completing her Ed.D on self-efficacy and academic writing, with a particular focus on non-traditional university students.

Michelle Reid has been a Study Adviser at the University of Reading since 2007. She has published study guides on report writing and time management and has an interest in supporting students making transitions to postgraduate level study. Michelle is a University Teaching Fellow. 